\title{
CRIANÇAS E NARRATIVAS: MODOS DE LEMBRAR E DE COMPREENDER O TEMPO NA INFÂNCIA
}

\author{
Andréa Borges de Medeiros*
}

\begin{abstract}
RESUMO: O texto resulta de uma pesquisa de doutoramento em processo de finalização que investiga as dinâmicas da memória na infância. Por meio da análise das elaborações das crianças na comunicação de suas lembranças através de narrativas, observa-se como se configura a habilidade das crianças para estabelecer relaçôes entre tempos. Propor às crianças que contem sobre o seu passado, sob a mediação dos artefatos produzidos no cotidiano escolar, pode proporcionar-lhes uma experiência narrativa com forte potencial para promover a compreensão da temporalidade histórica.
\end{abstract}

Palavras chave: Tempo. Narrativa. Infância. Memória.

CHILDREN AND NARRATIVES: WAYS OF REMEMBERING AND UNDERSTANDING TIME IN CHILDHOOD

ABSTRACT: This text is part of an almost concluded doctoral research aimed at discovering the dynamics of memory in childhood. Analyzing the children's constructions when they communicate their memories in narratives, we explore their abilities to establish relationships between times. Asking children to tell us about their past, based on objects they made earlier at school, can engage them in a narrative experience that might help them understand historical temporality.

Key words: Time. Narrative. Childhood. Memory.

Doutoranda no Programa de Pós-Graduação em Educação da Universidade Federal de Juiz de Fora (UfJF).E-mail: andreabmedeiros@ig.com.br 
ara ${ }^{1}$ estava sentada num banco de madeira que ficava num longo corredor da escola. A distância eu podia vê-la cabisbaixa, olhando para os próprios pés, que, suspensos do chão, balançavam-se para frente e para trás. Interessou-me aquela cena, não só pela estética que suscitava, mas também porque a menina estava quieta por demais, o que não condizia com a sua costumeira tagarelice e esperteza. Devagar me aproximei. Sentei ao seu lado naquele extenso banco. Perguntei o que estava acontecendo e ela, mais que depressa, respondeu: "Estou aqui esperando passar o efeito da lua cheia. Foi a tia quem mandou". “Como assim?". Perguntei. Ela então, muito convicta, completou:

É que eu estava na sala, aí peguei de novo o efeito da lua cheia e comecei a morder e a arranhar todos os meus colegas. Minhas unhas crescem quando é lua cheia e começam a arranhar. Não foi culpa minha, eu só estava virando lobisomem. A tia sabe disso, ela entende, me mandou ficar aqui do lado de fora até o efeito passar. Já está passando, eu já estou até conversando com você!

Impressionada com o realismo daquela narrativa, disse para Sara que informaria a professora sobre o fim daquele "efeito" inoportuno e perguntaria sobre a possibilidade do seu retorno para a sala. Abri a porta devagar, as crianças estavam sentadas no chão, em círculo, e a professora conversava com elas. Parecia propor alguma atividade que envolvia recortes de papéis coloridos e colagem. Havia tesouras e colas, desenhos e pinturas, livros de histórias e folhas de jornais. Vi que estava interrompendo e pensei que a minha intervenção poderia esperar. Sem dizer uma só palavra, tentei fechar a porta novamente quando ouvi alguém dizer: "Você encontrou com o lobisomem aí fora?". Foi o suficiente para fazer com que eu decidisse intervir, mas o meu movimento era incerto, porque me senti incomodada sobre o que eu deveria responder. Qual seria a melhor alternativa?

Por mais convincente que a menina tenha sido, narrando o motivo pelo qual estava fora de sala, eu não sabia como a professora e as crianças tinham compartilhado aquela história da "transformação". Não podia supor que "esperar o efeito da lua cheia passar" fizesse parte de um acordo.

Por isso, sem saber como deveria proceder, respondi que havia encontrado a Sara e que ela estava sentada no banco do corredor. Acrescentei que ela me informou que estava esperando o "efeito da lua cheia 
passar" para depois voltar para a sala. As crianças ficaram agitadas com o meu relato e foram logo dizendo que era assim que tinha que ser, ela deveria ficar de "fora" porque estava unhando as pessoas e estragando os trabalhos. Demonstravam curiosidade sobre o comportamento da colega e falavam todas ao mesmo tempo. Logo saíram da sala e foram conversar com ela. Eu e a professora nos entreolhamos, mas não interviemos. As crianças rodearam a menina, que ainda estava sentada no banco. Ela então se levantou. Sentindo-se amparada pelos colegas, adentrou a sala de aula e buscou o seu lugar na roda. Sentou-se no chão e as outras crianças fizeram o mesmo. O círculo se formou novamente, irradiando uma cumplicidade jamais vista. Uma criança então disse: "Pronto, já passou. Ela não é mais lobisomem!".

Não dava para dizer muita coisa. Eu não encontrava as palavras. A atitude das crianças foi surpreendente. Elas não ignoraram o comportamento agressivo da colega, mas criaram com ela uma parceria em seu "devaneio", construindo, desse modo, uma experiência coletiva. Foi então que a professora propôs uma conversa para depois do intervalo, o que de fato ocorreu.

Entretanto, para a análise que eu pretendo empreender neste texto, importa a relação deste acontecimento com outro, ocorrido um ano depois e que envolveu aquele mesmo grupo de crianças. Trata-se da memória daquela história da transformação da Sara em lobisomem, quando alguns artefatos recolhidos no arquivo da escola foram parar nas mãos delas, por ocasião de uma reorganização das produções recolhidas.

A prática de guardar as produçóes individuais e coletivas era comum naquela escola pública de periferia urbana. $\mathrm{O}$ arquivo de memórias abrigava os mais diferentes artefatos: fotografias, textos, desenhos, portfólios, brinquedos, retalhos de panos, restos e sobras das experiências vividas no cotidiano escolar. Isto implicava uma seleção, envolvia fazer escolhas sobre o que deveria ser preservado e o que poderia ser descartado. Não havia uma regra para o arquivamento das produções. $\mathrm{O}$ que alimentava aquele movimento de guarda era uma "vontade de memória” (Miranda, 2007, p. 9) partilhada por adultos e crianças. Assim, numa tarde em que nos dedicávamos a arrumar o arquivo mais uma vez, deparei-me com um acontecimento que, de fato, interveio nas minhas reflexões sobre as memórias das crianças e sobre os modos como elas se organizavam para narrar as suas experiências. 
Eu havia colocado sobre a mesa do refeitório alguns trabalhos. Preparava as etiquetas para identificá-los, colando-as por cima do papel pardo que os envolvia. Algumas crianças do segundo ano se aproximaram e se ofereceram para ajudar. Aproveitei aquela oportunidade e sugeri a elas que separassem por turmas os materiais que estavam sobre a mesa. Algumas folhas com desenhos se encontravam soltas, desvinculadas dos álbuns que elas já conheciam. Nelas havia alguns nomes. Em uma estava escrito o nome "Sara" e a marca de um rasgo, bem no meio da folha, indicava que ela poderia ter se rompido em duas partes. Uma fita de cola transparente a recompunha. Lembro-me de ter colado aquela folha, mas não sabia do que se tratava, porque não havia nenhuma anotação que identificasse aquela produção, a não ser o nome escrito a lápis no seu verso. Era a pista da autoria.

A concepção de que algo pode ser desvelado a partir de pistas tem fundamento nos estudos de Ginzburg (1987; 1989). Sob a designação de paradigma indiciário, o autor estabelece um método que se assemelha à caça dos detalhes do cotidiano, deixados como marcas da passagem dos seres humanos pelos contextos históricos e sócio-culturais. Os detalhes, tomados como indícios, são interpretáveis e dependem da maneira de olhar do pesquisador que busca as pistas daquilo que se pretende conhecer. Desse modo, o paradigma indiciário fundase no detalhe, no singular, e essa postura metodológica incide na relação que o investigador estabelece com o campo e com os dados obtidos. Tal paradigma subsidiou a minha interpretação dos pormenores aparentemente insignificantes que pude abstrair para empreender essa análise.

No dia em que o meu encontro com as crianças se deu naquele refeitório da escola, elas leram o nome escrito no verso do desenho que apresentava as flores coloridas. Foi o bastante para uma delas afirmar: "Foi no dia que ela virou lobisomem, olha aqui o rasgo no papel!".

Eu enxergava, naquele momento, a habilidade de "derivação" própria das crianças: sentidos que se inventam nos vestígios do tempo, frutos da imaginação em profunda conexão com a experiência. Era um encontro com o encantamento pelos mundos imaginados (Bachelard, 1988).

Quando Bachelard propõe investigar a imaginação e a memória, faz uma análise sobre o devaneio como uma forma de traduzir a entrega de corpo e de alma à imagem que encanta. Este ser que se entrega 
confunde-se com o sonhador que habita um mundo e com ele busca unidade. Unidades de mundo e unidades de devaneios convergem diante de todas as "aberturas" que o sonhador de mundos hesita, mas, mesmo assim, avança por elas sem conhecer divisão alguma, porque, ao percorrer imagens, se depara com outras que se desdobram em processos de embelezamento mútuo.

As crianças, como os poetas, entram neste mundo de imagens sem aspirar representá-lo, porém vivendo-o com todo o apetite para absorvê-lo (Bachelard, 1988). Apetites e mundos alimentam o sonhador, que se farta das "substâncias do mundo, substância densa ou rara, quente ou doce, clara ou cheia de penumbra segundo o temperamento de sua imaginação" (Bachelard, op. cit., p. 171). A apropriação da expressão mundos imaginados supõe, então, a abundância das imagens que configuram profundas contemplações e comunhões de devaneios.

Ao partilhar as suas lembranças, as crianças não se orientaram pelo conteúdo preservado no desenho das flores, mas sim pelo estrago da folha. A conexão que estabeleceram foi entre o gesto de rasgar durante a "transformação" e o efeito causado: a folha partida. Um gesto alimentado pelo "devaneio", pela imagem fantástica daquele ser híbrido. Para elas, a presença da fita de cola marcou a recomposição, o retorno a um convívio pacífico. Foi a fita que possibilitou a lembrança fiada e tecida na imaginação. Na imaginação do "avesso", ou do "reverso", porque no anverso, na página estampada pelo desenho, só havia a marca da agressão que a folha havia sofrido. As aprendizagens experienciadas na narrativa perpassavam o gesto e a imagem associada a ele. Estavam ligadas a uma "memória cósmica" e indicavam, para mim, o modo como as crianças deixaram-se impregnar pelas suas próprias fábulas criadas pelo seu universo imaginado. Elas falavam como se soubessem que as coisas sempre estivessem lá, comandadas por um único "sol dominador" (Bachelard, 2001, p. 112). A "memória cósmica” permitiu o ilustrado, o mundo da primeira vez, e por isso rompeu livre de qualquer exatidão.

Enquanto a folha passava de mão em mão, as narrativas eram partilhadas e os pactos de memória se confirmavam. Elas se desdobravam em outras que se diferenciavam na forma, mas não no conteúdo, ou seja, no protagonismo daquele "lobisomem" e nos estragos que ele podia fazer. A folha era a senha para o acesso à lembrança da monstruosidade. A fita de cola era a contra-senha que evidenciava a possibilidade de 
“cura". Ambas eram exibidas como a "prova" de que uma transformação tinha ocorrido naquele espaço/tempo de escola.

Foi então que a Sara se aproximou de nós. Negou a autoria em relação ao desenho das flores e interveio nas narrativas que as outras crianças partilhavam, interrompendo-as de maneira brusca. Disse que aquela história já tinha "passado", que "foi muito antes", porque no "tempo de agora" ela não virava mais "lobisomem". Logo se pôs a chorar.

Acolhi aquela menina. Aos prantos, ela se manifestou dizendo ainda que naquele dia do "lobisomem" fazia muito frio. Acrescentou que estava com "raiva" e, por isso, unhava e estragava as coisas. Apresentei-lhe novamente o desenho, mas a sua recusa foi decisiva para me fazer desistir. O seu choro se tornou intenso, dramático pranto, eivado de lágrimas.

O desenho ficou de lado e as outras crianças procuravam acalmála, dizendo que tudo já tinha "passado", pois elas haviam perdoado o "lobisomem". Algumas afirmavam que lobisomens não existiam, não eram seres reais, verdadeiros. A Sara então completou: "Naquele dia era verdade, mas agora não é mais. Eu já cresci e já aprendi. Eu não posso rasgar... eu tava com raiva... da minha mãe... ela tava namorando e o meu padrasto bate na Teca [a irmãzinha]... eu não gosto...”.

Houve um desenrolar daquele choro compulsivo e do relato daquela agressão. Um desenrolar que envolveu muitas pessoas, como a mãe da menina, por exemplo. Ela esteve na escola e, quando conversamos, nos informou que havia uma situação familiar conflituosa, proveniente do seu processo de separação do pai das meninas. Outras vezes, nos encontramos e aos poucos fui percebendo que a família se recompunha e, a cada dia, reconstruía as relações de afeto, o que se confirmou mais tarde quando a Sara partilhou comigo o seu sentimento em relação ao padrasto. Ela disse: "Ele já é como um pai para mim!".

A imagem de Sara como uma irmã protetora, andando a espreita do que poderia acontecer à pequena Teca, sempre revelou, para mim, a cumplicidade que existia entre elas e o amor que nutriam uma pela outra. Mas o olhar de ambas, a mirar a câmera, quando, numa festa junina, uma fotografia lhes apreendeu a imagem, capturou o meu próprio olhar e o levou ao encontro do soma infantil que Agamben (2005) situou como uma condição, um ambiente e um sentido que não abandonam a humanidade. A infância vista sob esse paradigma está liberta 
de uma temporalidade contínua em direção a um futuro longínquo, porque a sua experiência é tramada nas descontinuidades e nas rupturas. Da mesma forma que Sara, nós adultos somos passíveis de transformaçôes, de deixar-nos tocar pelos mundos imaginados que atravessam as janelas do porvir. São essas janelas que nos indicam a nossa transitoriedade. Através delas podemos ir e vir, construir e desconstruir, insistir e desistir.

Narrar sempre de novo a experiência partilhada, buscando refletir sobre as estratégias das crianças para produzir lembranças e comunicá-las, constituindo memórias e compreensóes sobre o tempo, é uma forma de ressignificar o passado no presente e apresentá-lo em sua novidade. Desse modo, puxei alguns fios de reflexão depois de presenciar os movimentos das crianças em torno do acontecimento que envolveu a Sara e a experiência coletiva em torno da história da sua transformação em lobisomem. Um deles foi o de que as crianças, quando em contato com algum artefato ou objeto de guarda, como foi o caso do desenho colado com fita de cola, criam contextos diferentes de interação e de comunicação de suas lembranças. Elas fazem isso narrando e buscando compreender a simultaneidade de suas açōes e participaçóes no mundo, mas a multiplicidade e a diversidade das reminiscências que surgem imbricadas na experiência rememorada variam de acordo com envolvimento delas na experiência coletiva.

Outro fio de reflexão foi que a folha restaurada pela fita de cola funcionou como um dispositivo, porque disparou as lembranças das crianças. Ela instigou outras composiçōes que extrapolaram o contexto da criação do desenho. As práticas que deram origem ao desenho não foram mencionadas. As crianças não se interessaram pela lembrança daquele momento de criação e nem mesmo pelas histórias sobre os outros desenhos que estavam sobre a mesa. Elas desfiaram as narrativas, criando um mosaico delineado por rupturas e entrecortado por histórias e lembranças outras, porém semelhantes no tema da metamorfose.

Quando as crianças tomaram o desenho das flores como referência para as suas lembranças, criaram uma relação com a memória que se constituiu pelos sentidos partilhados, nas lembranças sobre aquele rasgo no meio da folha e sobre a fita de cola que a recompunha. A experiência espaço-temporal que tocou as crianças se revelou nas suas narrativas e constitui-se em memória. 
Aos poucos fui observando o que ocorria. O protagonismo das crianças nas ações que partilhavam, nas decisões de colaborar com organização do arquivo, e nas histórias que contavam, instigou-me a pensar com força na experiência como "algo que nos passa”. Segundo Jorge Larrosa, "o sujeito da experiência seria algo como um território de passagem, algo como uma superfície sensível que aquilo que acontece afeta de algum modo, produz alguns afetos, inscreve algumas marcas, deixa alguns vestígios, alguns efeitos" (Larrosa, 2002, p. 24 ).

As crianças estavam abertas àquela passagem da experiência. Não importava encontrar o tempo em sua cronologia, porque o que lhes tocava, no momento que elas se depararam com aquele choro incontrolável da Sara, era a mudança no seu comportamento. A solidariedade que demonstraram foi fruto dessa compreensão. A história criada pela Sara no passado tinha um sabor de alegria, de invenção e de prazer na partilha daquela narrativa que se tornara lúdica. No presente, aquela história a incomodava, gerava conflito e ressentimento. A pesquisa então se abriu para mais essa dimensão da memória: o ressentimento. Dimensão inefável porque inaugura a possibilidade, por meio da análise das linguagens, de encontrar o que as crianças guardam "no mais íntimo de [seu] foro íntimo" (Bresciani \& Naxara, 2004, p. 9).

Há ainda a perspectiva da análise de uma lembrança sem data, mas ligada a uma estação. O frio, ao qual a menina se referiu, fazia parte de qual lembrança: aquela que a levava ao encontro da sua transformação ou a que trazia à tona a memória de uma agressão? Para Bachelard (1988), é a estação que constitui a marca fundamental das lembranças: "Que sol e/ou que vento fazia nesse [naquele] dia memorável?" (p. 111). $\mathrm{O}$ frio derivou da imagem, engrandecendo-a. As imagens do lobisomem e da lua cheia se misturaram com a sensação térmica, ou melhor, com a lembrança daquela sensação: a do frio, que permitiu uma transição entretempos, entre memória/imaginação e memória/ressentimento. As imagens associaram-se então ao universo do inverno como uma estação total. Esse universo fez com que todas as imagens exprimissem o mesmo valor: o do ressentimento. Isso pode se chocar com a afirmação de que "as estações da lembrança têm condão de embelezar" (p. 112).

$\mathrm{Na}$ infância, nem todas as estações são primaveras e o frio, que poderia trazer a imagem do aconchego de um colo que aquece, pode se transformar na imagem da mão que bate, prolongando o inverno. 
Contudo, as estaçôes "podem enganar, cumprir-se mal, descaracterizarse, imbricar-se" (Bachelard, op. cit., p. 112). Isso coloca um desafio para essa investigação: perceber os enganos das estações no signo da infância. Desafio que mistura nas cores da infância as múltiplas facetas da memória, como também o seu lado sombrio, que vem à tona nas brechas e nas subversōes dos sentidos da linguagem.

No caso da Sara e de suas lembranças, a meu ver, houve um avivar do devaneio. Ela poderia ter esquecido a história do lobisomem e jamais ter estabelecido alguma relação entre aquela experiência e a agressão que ela dizia ter ocorrido contra a sua irmãzinha. Mas o contato com artefato, ou seja, com o desenho reconstituído pela fita de cola, e a experiência com as narrativas das outras crianças tocaram-na profundamente. Um novo modo de lembrar se constituiu para ela, mas logo um conflito de memórias se estabeleceu: as lembranças partilhadas pelas outras crianças não mais se encontravam com as suas próprias lembranças.

No devaneio da monstruosidade daquele ser híbrido, ela pôde explicar a sua agressividade, mas talvez não se lembrasse, ou propositalmente quisesse esquecer pelo menos uma das consequências de seus atos: os estragos nos trabalhos de classe. Ela se incomodou com as abordagens das outras crianças sobre os feitos do lobisomem, que mesmo libertando-a de sua responsabilidade sobre os estragos e as agressões aos colegas, provocou-lhe uma emoção pelo passado presentificado. Foi então que a experiência de lembrança "ricocheteou o insondável" (Bachelard, 1988, p. 121), ou seja, perdeu-se na oportunidade de encontrar o seu fundo. Isso a fez se deparar, ainda criança, com uma infância que estava ali, entre um antes e um depois, "se constituindo por fragmentos no tempo passado, feixe mal feito de conhecimentos vagos" (p. 121).

Quando a Sara se deparou com as narrativas dos colegas sobre os estragos que havia causado, mesmo vendo o desenho reconstruído, agiu para além de suas lembranças e criou outra imagem, sem remetêla, no entanto, a nenhuma fábula, mas sim ao seu cotidiano familiar. Negou a autoria do seu desenho, mas não pode negar os estragos que provocou porque a memória coletiva foi mais forte que a sua individual. Criou a imagem do agressor e sobre ela fez uma nova comunicação de sua experiência espaço-temporal, proporcionando-me, dessa 
forma, enxergar o reencontro entre "universos de infância”, entre comunicações de experiências que se alteram e alternam conforme a intensidade do vivido, o que na perspectiva de Bachelard é a própria cosmicidade.

Essa compreensão que abarca a alma das crianças e dos poetas faz ressoar uma espécie de canto cósmico. Um canto que, nas crianças, se expande na capacidade de maravilhar-se, instaurando uma poética do cotidiano e da descoberta. Nos poetas, a expansão se dá através do lapso da palavra, que "não se limita a exprimir ideias ou sensações, mas que tenta ter um futuro" (Bachelard, op. cit., p. 3). Por esse viés, tanto os poetas quanto as crianças se tornam próximos porque vivem o porvir da linguagem. Neste porvir, a discussão sobre a memória encontra vigor na suposição de que há uma composição entre imagens e devaneios. As imagens como criações da lembrança na força viva da experiência espaço-temporal e os devaneios como oportunidades de transição entre as lembranças, porque elaboram esteticamente as imagens, impregnam a memória dos sentidos partilhados no cotidiano e nas relaçôes entretempos.

Desse modo, um caminho que se delineia para a continuidade desta reflexão avança não só em relação às imagens que as crianças criam na composição das suas memórias, mas também na conexão que elas estabelecem entre as imagens criadas no presente e as lembranças do passado. Esta conexão inaugura o inaudito através da retomada do passado. A narração é um dos caminhos para essa retomada, pois nela os sentidos são reconstruídos, o que não significa uma repetição do passado. A atitude narrativa é criadora e, por isso, sempre nova em relação ao passado.

Mas como apreender a atitude narrativa das crianças?

Trazer à tona as suas vozes sem nos apoderar delas pressupõe um rompimento com formulações que conformam um modelo de infância como espaço de "alheidade" ou "outridade". Esse modelo vê a criança como outro, ou seja, como alguém excluído de muitas esferas da vida social e cultural. Também a exclui de uma episteme sobre a própria ideia de infância, como também de uma compreensão ética e estética sobre a vida e as pessoas, além de outras esferas de inserção (Kohan, 1999).

A possibilidade de compreender a derivação, ou seja, o desejo que as crianças expressam nas palavras fora do tema, permitindo a elas transitar fora do assunto em pauta (Souza, 1994), promove um encontro 
com a perspectiva da capacidade mimética (Benjamin, 1994, 1995), melhor dizendo, a capacidade de produzir semelhanças e apropriar-se dos significados das palavras, produzindo sentidos outros. Esse processo ultrapassa o que poderia ser entendido como imitação, porque a criança, ao reconhecer as semelhanças, produz outras, criando um novo modo de sentir as coisas. Ela estabelece uma espécie de jogo e outras maneiras de produzir sentidos entram em cena, como, por exemplo, a atenção ao detalhe, àquilo que o olhar do adulto deixou escapar. Por esse motivo, a incompletude lhe pertence e abre caminhos para um $f a-$ zer sempre de novo.

A experiência na infância apresentada dessa forma estabelece outra relação com o espaço e com o tempo, porque parte do pressuposto de que a criança recolhe, no seu caminhar pelo mundo, imagens bem diferentes daquelas recolhidas pelo adulto. Ela olha as margens e este olhar instiga uma produção de sentidos próprios, pois as imagens que ela fixa pertencem ao inusitado, ao que olho traduz em encantamento.

Para Benjamin (1994), esse olhar marca o tempo de indefinição da infância, porque anuncia outras formulações e outros reconhecimentos em torno da produção de semelhanças.

Sob esse enfoque a criança deixa de ser o outro pesquisável, torna-se coparticipante da produção do conhecimento, da episteme da pesquisa. A sua linguagem movimenta a investigação, deixando à mostra o seu "estilo filosófico" de atuar sobre o mundo circundante, e revela a infância como categoria histórica e cultural, conforme as proposições de Benjamin (1994, 1995), Gagnebin (2005, 2007) e Agamben (2005). A concepção inspirada por esses autores valoriza a não soberania da criança sobre a linguagem. O suposto de que "a criança vê o que o adulto não vê mais" (Gagnebin, 2005, p. 180) refere-se a outro campo de percepção e de análise. A noção do prefixo in, na palavra infância, pressupõe uma ausência originária de linguagem, de razão, algo antes do logos, mas que, para aqueles autores, está longe de ser uma limitação ou impedimento. É nessa experiência inefável da criança que a linguagem deixa de se apresentar como totalidade e verdade, o que faz da infância $o$

(...) signo sempre presente de que a humanidade do homem não repousa somente sobre sua força e seu poder, mas também, de maneira mais secreta, mas tão essencial, sobre suas faltas e suas fraquezas, sobre esse 
vazio que nossas palavras, tais como fios num motivo de renda, não deveriam encobrir, mas sim, muito mais, acolher e bordar. (Idem, ibid., p. 181)

Sob tal paradigma, a memória, o tempo e a narrativa se constituem como um amálgama. As crianças, quando se lembram, transformam a lembrança em ação, ou seja, elas podem experienciar o passado rememorado, modificando os tempos narrados e a história presentificada. A experiência de narrar impele a criação de recursos cognitivos para processar imagens-lembranças. Nesse percurso emerge, para ela, a lembrança de si.

Num estudo recente publicado por Paul Ricoeur, há uma abordagem que merece destaque, porque traz o problema das lembranças para a constituição de uma memória. Segundo este autor, a transição entre o "o quê" da lembrança e o "quem" se lembra passa por uma discussão que decorre da relação que a tradição filosófica estabeleceu entre a memória e o passado, ou seja, refere-se a um processo antigo de investigação da "face objetal da memória", que tem o enigma da imagem como arremesso. Desde Platão e Aristóteles, o problema da presença da coisa ausente, "marcada pelo selo da anterioridade", atravessa muitas questões epistemológicas, como é o caso dos testemunhos e das representações sociais como explicação/compreensão para as abordagens que tomam como objeto de análise os acontecimentos ou as conjecturas que pontuam o passado histórico (Ricoeur, 2007).

Sobre essa discussão o autor se posiciona, tendo como referência a fenomenologia da memória. Para ele, há deliberadamente uma análise voltada para o objeto da memória, que passa por uma série de estágios, envolvendo o esquecimento e a lembrança, até chegar a uma espécie de memória refletida, associada a uma memória de si. Isso significa que uma questão de pesquisa em torno do que as crianças se lembram passa, necessariamente, por uma análise que deverá buscar os modos de organização dessas lembranças e as estratégias de narrativas.

Trata-se de uma análise que não poderá abster-se de observar os critérios e/ou recursos cognitivos para se chegar ao encontro do sujeito que lembra, passando por uma experiência de linguagem de dupla significação, qual seja, a que transita na infância entre a dimensão do signo, das palavras no seu sentido dicionarizável, e da semântica, do discurso que se constrói na cultura pelo viés dos sentidos (Agamben, 
2005). A dimensão objetal a que Ricoeur se refere está ligada, então, à superação da ideia de memória de um ego. O que é objetável, na memória do sujeito, não são as suas lembranças pessoais, mas os sentidos que perpassam as relaçóes socialmente engendradas no cotidiano. Portanto, o objetável da memória são os discursos traspassados pelo social.

É nesse tecido social que as histórias de adultos e de crianças se entrelaçam e se interrelacionam, entrecruzando conteúdos do passado individual e do passado coletivo. A escrita deste passado acontece, então, como um registro do fortuito que escapa ao escoamento de um tempo visto como linear e inaugura a força do insignificante e do fragmento para a construção de uma narrativa histórica. Compreender o passado e inscrevê-lo como memória, neste contexto, é reconstruí-lo com histórias.

Recebido em junho de 2009 e aprovado em novembro de 2009.

\section{Nota}

1. Os nomes próprios inseridos no contexto do texto são fictícios. Essa decisão foi tomada pela autora em função de preservar as identidades dos sujeitos envolvidos na situação de pesquisa.

\section{Referências}

AGAMBEN, G. Destruição da experiência e origem da história. Belo Horizonte: Editora da UFMG, 2005.

BACHELARD, G. A poética do devaneio. São Paulo: Martins Fontes, 1988.

BENJAMIN, W. Walter Benjamin. Obras escolhidas. Magia e técnica, arte e política. São Paulo: Brasiliense, 1994.

BENJAMIN, W. Walter Benjamin. Obras escolhidas II. Rua de mão única. São Paulo: Brasiliense, 1995.

BRESCIANI, S.; NAXARA, M. (Org.). Memória e (res)sentimento. Indagações sobre uma questão sensível. Campinas: Editora da UNICAMP, 2004 . 
GAGNEBIN, J.M. Sete aulas sobre linguagem, memória e história. Rio de Janeiro: Imago, 2005.

GAGNEBIN, J.M. História e narração em Walter Benjamin. São Paulo: Perspectiva, 2007.

GINZBURG, C. Mitos, emblemas, sinais. São Paulo: Companhia das Letras, 1989.

GINZBURG, C. O queijo e os vermes. O cotidiano e as ideias de um moleiro perseguido pela inquisição. São Paulo: Companhia das Letras, 1987.

KOHAN, W.O. Infância. Entre educação e filosofia. Belo Horizonte: Autêntica, 2005.

KOHAN, W.O.; KENNEDY, D. Filosofia e infância. Possibilidades de em encontro. Petrópolis: Vozes, 2000.

LARROSA, J. Notas sobre a experiência e o saber de experiência. Revista Brasileira de Educação, Rio de Janeiro, n. 19, p. 20-28, jan./fev./ mar. 2002

MIRANDA, S.R. Vontades de memória em um currículo de mudança. In: VI Encontro Nacional Perspectivas do Ensino de História: múltiplos ensinos em múltiplos espaços. Natal, 2007.

MOISÉS, M. A criação literária. Prosa. São Paulo: Cultrix, 1978.

RICOEUR, P. A memória, a história, o esquecimento. Campinas: Editora da UNICAMP, 2007.

SOUZA, S.J. Infância e linguagem. Bakhtin, Vygotsky e Benjamin. Campinas: Papirus, 1994. 